\title{
New genetic tests, new research findings: do patients and participants have a right to know-and do they have a right not to know?
}

\author{
Roger Brownsword* \\ Dickson Poon School of Law, King's College London and Bournemouth University, UK
}

\begin{abstract}
In the context of the systematic genotyping of UK Biobank's participants and the piloting of non-invasive pre-natal testing within the screening pathway for Down syndrome, this paper considers the plausibility, basis, scope, and weight of the claim that participants and patients have a right to know as well as a right not to know the results of the genetic analysis undertaken. It also considers the possible relevance to these issues of the landmark decision of the UK Supreme Court in Montgomery v Lanarkshire Health Board.
\end{abstract}

Keywords: the right to know; the right not to know; genetic tests; biobanks; feedback of incidental findings; non-invasive prenatal tests; Montgomery v Lanarkshire

\section{Introduction}

New technologies in healthcare, like new technologies in other sectors, disrupt settled practices and provoke new questions. ${ }^{1}$ In the context of human genetics, one such question concerns the 'right to know' and the 'right not to know'. ${ }^{2}$ This paper focuses on two recent developments—one, the systematic genotyping of UK Biobank's participants and the other,

An earlier version of this paper was given under the title 'Big Biobanks: A Case Study in Regulating Health Technologies' at the 2015 Symposium of the Sheffield Health Law and Policy Research Centre, School of Law, University of Sheffield, on June 29, 2015. I am grateful to those who gave me feedback at the symposium as well as to those who have commented as the scope of the paper has broadened; but, of course, the usual disclaimers apply. I should emphasise, too, that the views expressed in this paper are purely personal and should not be taken to represent or reflect the views of either the Ethics and Governance Council of UK Biobank (which I chaired from 2011-2015) or the National Screening Committee (of which I am a member).

$1 \quad$ See, e.g., M. Klang, Disruptive Technology (University of Gothenburg, 2006); and, for ample evidence of such disruption, both doctrinally and socially, see R. Brownsword, E. Scotford, and K. Yeung (eds), Oxford Handbook on Law, Regulation and Technology (Oxford: Oxford University Press, 2017).

2 As discussed, e.g., in the Nuffield Council on Bioethics, Genetic Screening: Ethical Issues (London, 1993); and R. Chadwick, M. Levitt, and D. Shickle (eds), The Right to Know and the Right Not to Know (Cambridge: Cambridge University Press, 2014). 
the proposed piloting of non-invasive pre-natal testing (NIPT) within the screening pathway for Down syndrome ${ }^{3}$ — that prompt further reflection on these claimed rights.

Announcing the first of these developments, in June 2015, UK Biobank released genotyped data on 150,000 of its participants, with the data on the remaining 350,000 participants due to be released later this year. With more than 800,000 markers targeted and, for each participant, some 73 million imputed SNPs, UK Biobank is now able to make available to researchers detailed genetic data. ${ }^{4}$ What, though, is the significance of this development for participants? Because UK Biobank is able to link the data and samples to particular identifiable participants, there is no insuperable practical obstacle to returning to individual participants (i) their own genotyped details (for example, a participant, worried about possible loss of cognitive function, might be interested in knowing whether he has the ApoE4 marker) or (ii) potentially clinically significant findings made by researchers—nor, equally, is there any insuperable practical obstacle to withholding such data or findings where it is known that the particular participant does not want feedback.

Turning to the second development, the attraction of NIPT (which operates by analysing fragments of fetal DNA that circulate in the mother's blood) is that it promises to reduce the need for an invasive amniocentesis test or chorionic villus sampling and, with that, to reduce the number of babies lost during pregnancies. ${ }^{5}$ However, because NIPT presents an

3 See J. Gallagher, 'Safer Down's test backed for NHS use’ (2016) (http://www.bbc.co.uk/news/health35311578) (last accessed September 25, 2016). Forrnally, the NSC has recommended to the Minister that the test should be piloted; and, at the time of writing, a ministerial announcement on the matter is awaited.

$4 \quad$ See, http://www.ukbiobank.ac.uk/scientists-3/genetic-data/ ( last accessed September 25, 2016).

$5 \quad$ For a successful trial led by Professor Lyn Chitty at Great Ormond Street Hospital, see http://www.rapid.nhs.uk/about-rapid/evaluation-study-nipt-for-down-syndrome (last accessed September 25, 2016). 
opportunity to provide information about the fetus that goes beyond the trisomies, ${ }^{6}$ even to the point of full genomic profiling, as well as returning information about the mother, ${ }^{7}$ it exacerbates concerns about the 'medicalisation' of pregnancy, the 'commodification' of life, the 'trivialisation' of decisions about abortion, the 'routinisation' of prenatal testing, and the 'stigmatisation of disability ${ }^{8}$, and so on. Inevitably, as NIPT is rolled out-and, with the Nuffield Council on Bioethics having announced a new Working Party to consider the ethical issues raised by potential future uses of $\mathrm{NIPT}^{9}$ — there will be questions about whether and what a pregnant woman has a right to know, or not to know.

In response to these developments, regulators might strive to strike a reasonable 'balance of interests', designed to maximise the health-related benefits while, at the same time, minimising any possible harms to patients or research participants. Or, they might encourage clinicians and researchers to agree on a 'responsible' approach that is then articulated in professional codes of practice. However, if we believe that the regulatory environment should be built around 'the right to know' and 'the right not to know', implying (among other things) that it is for individual patients and participants, rather than communities of clinicians and

$6 \quad$ For example, Sequenom's MaterniT 21 PLUS 'can tell you if you are having a boy or a girl, and screens for both common and rare chromosomal abnormalities. The test screens for trisomy 21 (Down syndrome), trisomy 18 (Edwards syndrome), trisomy 13 (Patau syndrome), and many others that can affect your baby's health': see https://sequenom.com/tests/reproductive-health/maternit21-plus\#patientoverview (last accessed April 25, 2016).

$7 \quad$ See, e.g., K. Oswald, 'Prenatal blood test detects cancer in mothers-to-be', Bionews 739 (2015) at http://www.bionews.org.uk/page_503998.asp. (last accessed September 25, 2016).

See, e.g., the exchange at Prime Minister’s Questions on May 4, 2016: see http://www.christianconcern.com/our-concerns/abortion/prime-minister-questioned-on-screening-outpeople-with-downs-syndrome (last accessed September 25, 2016). And, 'Sally Phillips explores the impact of a new screening [test] for Down's Syndrome in BBC Two's A World Without Down's Syndrome?' at http://www.bbc.co.uk/mediacentre/latestnews/2016/world-without-downs-syndrome (last accessed October 15, 2016).

See, http://nuffieldbioethics.org/news/2016/new-project-on-non-invasive-prenatal-testing/ (last accessed April 19, 2016). For a very helpful background paper, see Vardit Ravitsky, 'Non-Invasive Prenatal Testing (NIPT): Identifying Key Clinical, Ethical, Social, Legal and Policy Issues': available at http://nuffieldbioethics.org/wp-content/uploads/NIPT-background-paper-8-Nov-2015-FINAL.pdf (last accessed April 27, 2016).. 
researchers, to decide whether and, if so, which results and findings are returned to them, such responses will seem inappropriate.

The paper is in three principal parts. In the first part, the general plausibility of a claimed right to know and right not to know is considered; in the second, with a view to developing an improved understanding of these rights, a number of responses and counter-responses to patients or participants who advance such claims are explored; and, in the third, the possible relevance to these issues of the landmark decision of the UK Supreme Court in Montgomery $v$ Lanarkshire Health Board ${ }^{10}$ —a decision that arguably supports both claimed rights—is assessed.

\section{The plausibility of a claimed right to know and right not to know}

On the face of it, the proposition that there is a general 'right to know' as well as a 'right not to know' seems both vague and implausible. By whom, and against whom, are these rights claimed? What kind of information is covered by these rights? Simply because there is something that I would like to know (for example, the secret of a particular conjuring trick or the recipe for Coca-Cola), it surely does not follow that I have a claim-right against those who have the information in question that they should disclose it. After all, the whole point of recognising a right to informational privacy and confidentiality (including trade secrets) is to deny that there is a general right to know. On the other hand, there are some particular contexts and some particular circumstances in which the claimed right to know is plausible. For example, it seems reasonable that insurers should expect their prospective insured to disclose facts that are material to the risk to be covered (but not perhaps the results of genetic tests), that employers should expect prospective employees to disclose their employment history, that finance companies should expect those who apply for credit to disclose their

10 [2015] UKSC 11. 
financial circumstances, and so on. It might also seem reasonable to expect others to make the equivalent of an easy rescue by passing on potentially life-saving information. Indeed, precisely such an analogy has been advanced to question whether biobanks would be justified either in adopting 'no feedback' protocols or sticking to such a protocol where they have potentially life-saving information that relates to a particular identifiable participant. ${ }^{11}$

For the purposes of this paper, the fact that the context for the claimed rights is, broadly speaking, medical, might strike us as less important than the fact that $\mathrm{A}$ is making claims in relation to information that is 'about A', that is 'personal' to A. Some might accept, without more, that A has a perfectly reasonable expectation that B should disclose, or refrain from disclosing, this information-information, after all, that is about A-if this is what A wants. If so, then, where a participant or a patient wishes to know about their genotyped data or their (or their baby's) genetic profile, they will have the right to know; and, if they do not wish to have this information, they can assert their right not to know.

However, it might be argued that, while it is necessary that the information is about A, this is not sufficient. It should not be forgotten that, if A has the claimed rights, A's control over the information in question is privileged; armed with these rights, A may demand to know or not to know regardless of how any 'balance of interests' stands. Some might argue, therefore, that the rights at issue are only plausible and sufficiently specific where they relate to information that not only concerns A but that also relates to A's vital interests, such as A's physical and psychological well-being. On this basis, it might be proposed that (i) where B

11 See, e.g., C. Heeney and M. Parker, 'Ethics and the Governance of Biobanks' in J. Kaye, S.M.C. Gibbons, C. Heeney, M. Parker and A. Smart, Governing Biobanks (Oxford: Hart, 2012) 282, at 296, where the authors remark that a no feedback approach has fallen out of favour in those cases where research might 'produce very clear evidence of a serious harm which might be avoided by an easily available intervention and where there exists something akin to a duty of easy rescue.'; and D. Beyleveld and R. Brownsword, 'Research Participants and the Right to be Informed', in P. R. Ferguson and G. T. Laurie (eds), Inspiring a Medico-Legal Revolution (Essays in Honour of Sheila McLean). (Farnham: Ashgate, 2015) 173. 
has information that is about A (ii) that A does not also have, and (iii) where that information relates to A's physical or psychological well-being, then (iv) if A wishes to have that information, B has a duty to disclose it to A (reflecting A's claimed 'right to know'), and (v) if A does not wish to have that information, B has a duty not to disclose it to A (reflecting A's claimed 'right not to know'). Hence, if the findings following the use of NIPT or genetic analysis (by a biobank or researchers who access the resource) are about A and relate to A's physical or psychological well-being, then A has the claimed rights in relation to B (who has the information in question).

To be sure, these remarks invite a number of questions-for example, whether, in the case of NIPT, information about A's unborn baby should be treated as information about A, the

mother ${ }^{12}$ - and there is more work to do in grounding and refining the claimed rights so articulated. Nevertheless, as expressed, the rights surely satisfy a test of initial plausibility.

\section{Responding to A's claimed rights}

Let us suppose that, in our focal cases, A claims a right to know, or not to know, against B (whether a screener, biobank manager or curator, or researcher). In each case, B might contest A’s claim and might do so in more than one way. For example, B might argue:

- Screening and research contexts are rights-free zones.

- Some rights are recognised but not either of the rights claimed by A.

- The claimed rights are recognised but, because A has consented to the terms and conditions of screening and research participation which exclude those rights, A has no claim.

- The claimed rights are recognised but they are not engaged because the information in question falls outside the scope of the rights.

For a response to this question, see the text at 3.4 below. 
- The claimed rights are overridden by conflicting rights (or by compelling considerations of the 'public interest').

We can say a few words about each of these responses and sketch how, in turn, A might reply.

\subsection{Screening and research contexts are rights-free zones}

To assert that health care in general, or more particularly public screening programmes and biobank research, are rights-free zones is not to suggest that screeners and researchers have no ethical commitments; it is simply to deny that 'respecting the rights of others' is the relevant test of doing the right thing. Rather, the justification for proposed public health interventions or practices is that they promise to promote the general utility; in clinical settings, medical professionals strive to avoid doing any harm as well as trying to do some good for patients; and, similarly, researchers are guided by their ethical responsibility to act in a way that will advance their knowledge and understanding of disease, diagnostic tests, and effective therapies while returning findings only if they will be of net benefit to participants.

In reply, A might take a high road or a low road. The high road involves showing that a rights-based ethic has better theoretical credentials than any of its rivals (whether utilitarian or duty-based). For example, A might argue that, because ethicists assume that humans have the capacity for agency (indeed, moral agency), and because the logic of agency compels us to recognise that certain generic conditions are conducive to our agency (whatever our particular purposes or projects), then agents must regard themselves as having claim rights against one another with regard to the protection, preservation, and promotion of the 'agency commons' ${ }^{13}$

13 Seminally, see A. Gewirth, Reason and Morality (Chicago: University of Chicago Press, 1978); and D. Beyleveld, The Dialectical Necessity of Morality (Chicago: University of Chicago Press, 1991). 
Alternatively, taking a lower road, A might argue that the recognition of rights is already implicit in public screening and biobanking practice. Quite apart from any particular statements made about the legitimate interests of those who are screened or who are research participants, where practice is to 'invite' individuals to be screened and to seek 'volunteers' to participate in research, the clear implication is that acceptance is optional. It certainly follows that taking part in screening or research is not required; and, should attempts be made to coerce individuals to participate, this would seem to infringe their prior claim-right not to be compelled to be screened or to participate in research projects. In other words, if the default position in relation to current practice is that individuals have a right not to be conscripted, then this undermines any claim that we are in a rights-free zone.

\subsection{The particular rights are not recognised}

Even if it is conceded that patients and participants do have some rights, it might be objected that the claimed rights are simply not recognised. Witness, in particular, the practice of biobanking where, subject to one or two exceptions (strikingly so in the terms and conditions for participation in the Estonian Genome Project ${ }^{14}$ ), the general rule is that participants are not granted either a right to know or a right not to know. ${ }^{15}$ To be sure, the Estonian position is in line with Article 10.2 of the Convention on Human Rights and Biomedicine (according to which 'Everyone is entitled to know any information collected about his or her health.

Compare, R. Brownsword, 'Friends, Romans, and Countrymen: Is There a Universal Right to Identity?’ (2009) 1 Law Innovation and Technology 223. And, for a recent evaluation and application of the Gewirthian argument, as elaborated by Beyleveld, see the various contributions in P. Capps and S.D Pattinson (eds), Ethical Rationalism and the Law (Oxford: Hart, 2017).

See, e.g., the survey in Ethics and Governance Council of UK Biobank, Feedback of Health Related Findings: Foreground Principles and Background Perspectives (London, 2015). 
However, the wishes of individuals not to be so informed shall be observed') ${ }^{16}$ as well as Article 5(c) of the UNESCO Declaration on the Human Genome (which endorses the 'right of every individual to decide whether or not to be informed of the results of genetic examination and the resulting consequences'). However, the United Kingdom has not signed up to the former Convention (although, admittedly, not because of its position on the rights at issue); and the latter Declaration, while not to be ignored, is largely symbolic and aspirational and, arguably, something of an ethical cocktail, mixing liberal rights with rather conservative dignitarian ideas. ${ }^{17}$ So, we cannot summarily dismiss the assertion that the claimed rights are not actually recognised in the United Kingdom.

If this suffices to place the burden of justification on A, it will be for A to show that, where NIPT is used or when in the course of the analysis of biobank genetic data, findings are made that potentially concern A's physical or psychological well-being, A has a 'reasonable expectation' that the findings should be returned or not returned (in line with A's will). By reference to which criterion, though, is A to show that this expectation is a reasonable one?

First, A might invoke the common law. Thus far, at any rate in English law, the question of whether A might succeed in a tort claim were screeners who use NIPT to decline to return findings that A wished to have (or if they were to return findings contrary to A’s known wish not to have feedback) has barely surfaced. By contrast, there has been much discussion of whether a participant might succeed against a biobank researcher in a tort claim for wrongful

\footnotetext{
16 See, too, Article 17.3 of Recommendation CM/Rec (2016) 6 (on research on biological materials of human origin) for the right not be informed.

17 For the latter, see e.g., Article 4 (no financial gain to be made from the human genome in its natural state) and Article 11 (prohibiting practices, such as human reproductive cloning, that are contrary to human dignity). Generally, see D. Beyleveld and R. Brownsword, Human Dignity in Bioethics and Biolaw (Oxford: Oxford University Press, 2001); R. Brownsword, 'Bioethics Today, Bioethics Tomorrow: Stem Cell Research and the "Dignitarian Alliance”'(2003) 17 University of Notre Dame Journal of Law, Ethics and Public Policy 15, 'Stem Cells and Cloning: Where the Regulatory Consensus Fails' (2005) 39 New England Law Review 535, and 'Human Dignity from a Legal Perspective' in M. Duwell, J. Braavig, R. Brownsword, and D. Mieth (eds), Cambridge Handbook of Human Dignity (Cambridge: Cambridge University Press, 2014) 1.
} 
non-disclosure of relevant individual findings. ${ }^{18}$ The consensus is that English law does not clearly support such a claim; and, if the legal test turns on whether it is 'fair, just, and reasonable' to place researchers under a feedback responsibility, this seems merely to restate the original question of whether the claimant's expectation is a reasonable one. Whether or not the decision of the UK Supreme Court in Montgomery v Lanarkshire Health Board might impact on this is a matter to which we will return in the third part of the paper.

Secondly, A might claim that the researchers or screeners had formally or informally signalled that feedback would be given. Given that the anticipated benefits of NIPT depend upon the results of the test being returned, it is unlikely that screeners will provoke claims based on a right to know—at any rate, not in relation to the primary results of the test. By contrast, many biobanks have well-advertised 'no feedback' policies, suggesting that A has no reasonable expectation of being informed. Even though such policies might be expressed ambiguously in terms that leave it unclear whether the biobank regards itself as having a duty not to return findings or as having no duty to return findings (thereby retaining a discretion to return findings), it is clear that 'no feedback' amounts to a denial of participants having a claim-right to know.

Thirdly, in the context of biobanking, A might plead an expectation, shared by others, that because participants assist researchers in various ways, the latter should reciprocate by giving appropriate feedback. ${ }^{19}$ However, the fact that others share A's expectation does not make anyone's expectation reasonable. Possibly, the claim for reciprocity might be grounded in

\footnotetext{
18 Seminally, see C. Johnston and J. Kaye, 'Does the UK Biobank have a Legal Obligation to Feedback Individual Findings to Participants?’ (2004) 12 Medical Law Review 239.

19 For evidence of such an expectation, see, e.g., J. Bovenberg, T. Meulenkamp, E. Smets, and S. Gevers, 'Always expect the unexpected: Legal and social aspects of reporting Biobank research results to individual research participants' (Nijmegen: Radboud University, Centre for Society and Genomics, 2009); and Wellcome Trust and Medical Research Council, Assessing Public Attitudes to Health Related Findings in Research (London, 2012).
} 
some other way-for example, by drawing on the relationship of 'entrustment' between participants and researchers ${ }^{20}$; but it is not enough that the de facto expectation is widely held by participants.

Fourthly, A might rely on settled custom and practice, whether with regard to the use of NIPT or in biobanking. Even if the screeners or researchers with whom A deals have not explicitly declared their position in relation to the return of findings, general custom and practice might suffice to ground A's reasonable expectation that the claimed rights are recognised.

More ambitiously, A might argue that, irrespective of such contingent indicators, the claimed rights are immanent within our understanding of such key concepts as property, privacy, autonomy and agency (and our understanding of their associated rights). The anchor for such an argument lies in each agent's critical interest in the free construction of his or her personality (or identity) — that is to say, each agent being free to be who they want to be, to form the relationships that they want to have, and to pursue the interests that they choose to have, and so on. ${ }^{21}$ Such a critical interest includes an interest in informational selfdetermination that bridges both well-being and autonomy. In an age of burgeoning genetic information, some agents, preferring to be aware of risks and to manage them, will want to know as much as they can about the details of their genetic profile; but others will prefer not to anticipate their futures and to cross whatever bridges have to be crossed as and when they meet them-23andMe will not be for them. While the former will claim a right to know, the latter will insist on a right not to know. However, both rights are grounded in the root interests of human agents and, if denied, there is a diminution in both agent autonomy and

$20 \quad$ For such an argument, see H.S. Richardson, Moral Entanglements: The Ancillary-Care Obligations of Medical Researchers (New York: Oxford University Press, 2012).

21 Compare Mireille Hildebrandt, Smart Technologies and the End(s) of Law (Cheltenham: Edward Elgar, 2015) at 80, where privacy is defined as a right to be free from 'unreasonable constraints on the construction of one's own identity'. 
agent well-being. If A wants to argue for the essential connectedness of the two claimed rights, this is perhaps the way to do it. ${ }^{22}$

Focusing on the right to know, A might try to strengthen the claim by joining the debates about the recognition and allocation of proprietary rights in relation to both donated samples and personal data. ${ }^{23}$ Even if these debates are not yet resolved in A's favour, it is arguable that, because property rights are 'preclusionary' ${ }^{24}$ (in the sense that 'if $\mathrm{x}$ is mine, then I need say no more to justify the decisions, even apparently unreasonable decisions, that I make about access to $\mathrm{x}$ - -implying that we should recognise proprietary rights only over important objects), there is a strong case for treating information relating to an agent's own physical and psychological well-being as the object of a property right. If such information is then so treated, A surely has a better claim than any other agent to be the relevant rights-holder. If A can simply say in relation to such information 'This is my property; it is mine', this readily explains and justifies A's demand to have findings returned; and, although it might require a bit more work, it might also explain and justify A’s insistence on not having feedback.

22 Compare the analyses in C.M. Halliburton, 'How Privacy Killed Katz: A Tale of Cognitive Freedom and the Property of Personhood as Fourth Amendment Norm’ (2009) 42 Akron Law Review 803; and J. Husted, 'Autonomy and a Right Not to Know', in Chadwick R. et al (n 2) 24. Compare, too, the approach to 'best interests' in Aintree University Hospitals NHS Foundation Trust v James [2013] UKSC 67 (where the significance of a particular patient's attitude to matters of life and death is emphasised).

See, e.g, the comprehensive survey of the law in relation to detached body parts in R. Hardcastle, Law and the Human Body: Property Rights, Ownership and Control (Oxford: Hart, 2007) and the positions taken in, e.g., R. Brownsword, 'Property in Human Tissue: Triangulating the Issue', in M. Steinman, P. Sykora, and U. Wiesing (eds), Altruism Reconsidered: Exploring New Approaches to Property in Human Tissue (Aldershot: Ashgate, 2009), 93; and Sarah Devaney, 'Tissue Providers for Stem Cell Research: the Dispossessed' (2010) 2 Law, Innovation and Technology 165. For the proprietary argument in relation to personal data, see, e.g., J. Lanier, Who Owns the Future? (London: Allen Lane, 2013); and N.Purtova, ‘The Illusion of Personal Data as No One’s Property’ (2015) 7 Law, Innovation and Technology 83.

As argued in D. Beyleveld and R. Brownsword, Human Dignity in Bioethics and Biolaw (Oxford: Oxford University Press, 2001) Ch. 7. 
A might also plead the protean concept of privacy in support of the claimed rights. ${ }^{25}$ For example, if we treat privacy as a right to maintain a state of psychological separateness, or a right not to be subject to unwilled 'intrusions', or as a right to be let alone, any one of these versions seems to support the idea that $\mathrm{A}$ has a right not to know in relation to information that is personal to him or herself. ${ }^{26}$ Alternatively, if we treat privacy as an asset that we can deploy in developing our relationships with others, ${ }^{27}$ and particularly if we limit what is private to a particular class of sensitive personal information, this seems to support the idea that A has a right to know in relation to findings that are sensitive in this way.

Whatever we make of these several arguments, there is more than enough in them to put the burden of rebuttal back upon those who decline to recognise the claimed rights.

\subsection{A has given a consent such that the benefit of the rights has been waived}

If we treat the claimed rights as being subject to the agent right-holder's will, then A may authorise acts that would otherwise amount to an infringement of her rights; and the standard way in which A so authorises such acts is by giving her free and informed consent to those acts.

If $\mathrm{A}$, having a right to know, consents to no return of results, then other things being equal $\mathrm{A}$ is precluded from complaining that results have not been returned. This is not another way of saying that A has the right not to know. By consenting, A changes the requirement of a right to know to a permission to withhold, but not to a prohibition on disclosing. The same applies mutatis mutandis to A's right not to know. Hence, if A consents to the return of results, then

25 Compare $R$ (Tracey) v Cambridge University Hospitals NHS Foundation Trust and others [2014] EWCA Civ 822 (for the application of privacy to a patient's right to be consulted about a DNACPR order). 
other things being equal $\mathrm{A}$ is precluded from complaining that findings have been returned; but, this is not another way of saying that A has the right to know. By consenting, A changes the prohibition associated with the right not to know to a permission to return results, but not to a requirement to disclose. What, though, is the significance of the 'other things being equal' caveat?

First, A's consent will be valid only if A has the capacity to consent, if the consent is given freely and on an informed basis, and if the consent is clearly signalled. ${ }^{28}$ Each of these conditions invites further analysis, always remembering that, because $\mathrm{A}$ is authorising an act that would otherwise violate her rights, we need to be confident that it is her will to license such an act.

Secondly, in relation to the use of NIPT, there is an understandable concern that, in practice, a screening pathway might become quite difficult to avoid. To the extent that the norm is to return the primary results of the NIPT, this might be relatively unproblematic. However, if the NIPT consent forms state either that no incidental findings will be returned or that all findings will be returned, and if asking a patient to sign off on these terms is all very routine, the 'consent' obtained might be vulnerable to the challenge that it is neither free nor properly informed.

Thirdly, in the context of big biobanks, participants sign up to a set of terms and conditions. In principle, a single signature by a participant confirming that the terms and conditions have been read and understood and that they are accepted might suffice. ${ }^{29}$ However, where the terms and conditions involve a waiver of the benefits of prior rights—and if the claimed

$28 \quad$ For systematic analysis, see D. Beyleveld and R. Brownsword, Consent in the Law (Oxford: Hart, 2007). Research—From Theory to Practice, from Practice to Theory (Springer, 2016) 175. 
rights are such prior rights-it is imperative that participants are given fair warning of the significance of what they are signing up to. Where there is to be no feedback, it is important that participants understand that this is not a personal health check; and, where the protocol is to return some findings (without any opt out) participants need to be warned that they might receive unwelcome health alerts, many of which will prove to be false alarms. If the format of the consent forms is such that, for each right there is a specific and explicit authorisation, this might be a more promising design; but, even then, it will not do if prospective participants are simply told at enrolment 'to sign, here, here, and here.'

\subsection{The information in question falls outside the scope of the recognised rights}

In response to A's claimed rights, it might be argued that the information falls outside the scope of the right. For example, B might challenge A's right to know about the health status of her baby on the ground that this is information about 'another', not about A herself. In support, B might point to Attorney General's Reference No 3 of $1994^{30}$ where the House of Lords rejected the Court of Appeal's view that the fetus should be 'viewed as an integral part of the mother ${ }^{31}$; but A might counter with the jurisprudence of the European Court of Human Rights according to which a human fetus is not to yet to be treated as a direct holder of rights. ${ }^{32}$ Given such inconclusive legal signals, a possible response for $\mathrm{A}$ is along the lines that, even if the baby is not integral to the mother, so long as the mother is recognised as having a right to terminate her pregnancy, it would be incongruous to deny her access to information that is relevant to that decision. Alternatively, A might try to reframe the right as one that centres, not on information that is 'about her', but as information the disclosure or

\footnotetext{
[1996] QB 581 (CA); [1997] 3 All ER 936 (HL).

$31 \quad$ [1996] QB 581, 598.

32

See, Vo v France (Application no. 53924/00) (Grand Chamber, July 8, 2004); Evans v United Kingdom (Application no. 6339/05) (Grand Chamber, April 10, 2007).
} 
non-disclosure of which clearly touches and concerns her physical or psychological wellbeing. If this latter approach is accepted, it succeeds in by-passing the difficult question of whether the baby should be treated as integral to the mother. ${ }^{33}$

B might also question the scope of A's right to know where the information in question is of such uncertain significance that A could not act upon it. Recognising the potential uncertainty of genetic information, the different degrees of seriousness of findings, and different grades of actionability, we might place findings on one of three lists: (1) a 'white list' (results should be returned), (2) a 'grey list' (results may be returned), and (3) a 'black list' (results should not be returned). ${ }^{34}$ But, then, even if the information clearly relates to a serious condition and is treatable (as per the 'easy rescue' scenario), a proviso for lawful use seems appropriate. For example, what if screeners suspect that the mother plans to use her NIPT results in order to determine the sex of the baby with a view to engaging in unlawful sex selection? ${ }^{35}$ If it were known that the mother was using NIPT in order to prepare for an unlawful termination, and even though the two certifying doctors are the immediate gatekeepers of lawful terminations, there would be good reasons to withhold the information. On the other hand, if there were merely a suspicion of, or a possibility of, the woman having an unlawful intention, this would be more problematic - after all, there will be many women who simply want to know (but not act on knowing) the sex of their baby. ${ }^{36}$ For present purposes, it suffices to say that, as a general principle, results should not be returned where this would constitute an act of

\footnotetext{
33 See, further, R. Brownsword and J. Wale, 'The Development of Non-Invasive Prenatal Testing: Some Legal and Ethical Questions’ (2016) 24 Jahrbuch für Recht und Ethik 24 (forthcoming). involving biobanks and archived data sets' (2012) 14 Genetics in Medicine 361. Prenatal Testing in England and Wales' (2016) 16 Medical Law International (DOI: 10.1177/0968533216646154); and R. Brownsword and J. Wale (n 33).
} invasive prenatal testing to test "purely for information”' (2015) 29 Bioethics 19. 
assistance with what is known to be a prospectively unlawful act — the most pressing example of which is unlawful sex selection. ${ }^{37}$

\subsection{A's right is overridden by a higher order right (or by a compelling consideration of the 'public interest')}

In principle, A's right to know or not to know may be overridden by a higher ranking conflicting right or by some compelling consideration of the public interest. Given the different ways in which A might try to ground and characterise these rights, their ranking rather depends on which account is accepted as the most coherent. On their strongest interpretation, A's claimed rights relate to an agent's fundamental interest in identity or in their physical and psychological well-being; even on a less high-ranking interpretation, the rights are characterised as protecting A's proprietary or personality interests. As such, these are rights that protect either vital or serious agency interests and they will not be easily outranked by conflicting rights. Similarly, with such high-ranking rights at stake, a public interest justification will have to be related to some kind of emergency and not merely an all things considered but routine balancing of interests. A's rights 'trump' routine justifications and, if public interest arguments are to operate, so to speak as 'super-trumps', they need to be something exceptional.

Biobank governance offers some exemplars for the tension between participants’ rights and public interest considerations, one of which arises where access is sought for reasons that are not explicitly authorised by participants in their consents but where this would serve the public interest—for example, in order to assist with the investigation of a serious crime or in

\footnotetext{
37 See, A. Hall, A. Bostanci, and S. John, Ethical, legal and social issues arising from cell-free fetal DNA technologies (PHG Foundation, 2009); (available http://www.phgfoundation.org/download/ffdna/ffDNA_appendix.pdf. ).
} 
order to help with the identification of victims following a major incident or disaster. ${ }^{38}$ In fact, in both these examples, the 'public interest' might be decomposed into a number of 'rights' that would be served by granting access (in the latter case, interestingly, pleading a family's 'right to know' about the fate of a loved one), in which case the question assumes the form of making a choice between conflicting rights. Without such a decomposition of the claim, at a time when the public interest is being pitched against individuals being able to assert rights that retard public health projects, there is a debate to be had about the relationship between the rights paradigm and public interest justifications-but this is not the place to have it. ${ }^{39}$

\section{After Montgomery}

In recent years, there have been some important developments in the UK's medical law jurisprudence. ${ }^{40}$ Amongst these developments, the decision of the UK Supreme Court in Montgomery v Lanarkshire Health Board stands out as a potential 'landmark'. ${ }^{41}$ Potentially, this is not just a leading case that materially reduces the range and relevance of the so-called Bolam test, ${ }^{42}$ it instates a radically new approach to the relationship between doctors and patients that might one day shape judicial thinking on the relationship between researchers

For discussion, see R. Brownsword (n 29); and, for some acute remarks on the tension in such scenarios, see For an extremely helpful survey, see J.R. Reidenberg, R. Gellman, J. Debelak, A. Elewa, and N. Liu, Privacy and Missing Persons After Natural Disasters (Washington DC and New York, NY: Center on Law and Information Policy at Fordham Law School and Woodrow Wilson International Center for Scholars, 2013).

See, further, R. Brownsword, 'Rights, Responsibility and Stewardship: Beyond Consent', in H. Widdows and C. Mullen (eds), The Governance of Genetic Information: Who Decides? (Cambridge: Cambridge University Press, 2009) 99.

For consideration of some of these case-law developments, including Aintree University Hospitals NHS Foundation Trust v James [2013] UKSC 67, Greater Glasgow Health Board v Doogan [2014] UKSC 68, and Montgomery v Lanarkshire Health Board [2015] UKSC 11, see R. Brownsword, 'Axiological Pluralism: Conflict in the Hospital, Resolution in the Courts' (forthcoming). 
and participants (even though this relationship was not directly at issue in Montgomery). After sketching the 'new approach' in Montgomery, we can assess its significance for the claimed rights.

\subsection{Montgomery: the New Approach}

The principal question in Montgomery was whether a pregnant woman who was a diabetic, and whose pregnancy was regarded as high-risk requiring intensive monitoring, should have been informed that there was a risk of shoulder dystocia and given the option of delivery by Caesarean Section. Instead, she was not made aware of this particular risk; the risk eventuated during an attempted vaginal delivery; and, as a result, the baby was born with severe disabilities. The lower courts, following the Bolam principle, held that the acts of the consultant obstetrician and gynaecologist who did not disclose the risk, and who was by her own admission reluctant to steer women towards a Caesarean Section, was sufficiently supported by medical practice. However, the UK Supreme Court, resoundingly rejecting the applicability of the Bolam test to such matters of patient information and physician disclosure, held that the relationship between clinicians and patients must be rights-respecting rather than paternalistic and that patients have a right to be informed about their options (together with their relative benefits and risks).

In a few paragraphs, the Supreme Court rewrote the legal framework governing the relationship between physicians and patients. First, the Court recognised that 'patients are now widely regarded as persons holding rights, rather than as the passive recipients of the care of the medical profession'. ${ }^{43}$ Secondly, the Court noted that patients, while not medical experts, are not wholly uninformed. Accordingly, it would be 'a mistake to view patients as uninformed, incapable of understanding medical matters, or wholly dependent upon a flow of

\footnotetext{
$43 \quad$ [2015] UKSC 11, para 75.
} 
information from doctors', from which it followed that it would now be 'manifestly untenable' to make this 'the default assumption on which the law is to be based'. ${ }^{44}$ Thirdly, professional guidance to doctors already reflects these changes by encouraging 'an approach based upon the informed involvement of patients in their treatment'. ${ }^{45}$ Signalling a distinct movement away from medical paternalism and patient-dependence, the new approach is built on mutual rights and responsibilities, treating patients 'so far as possible as adults who are capable of understanding that medical treatment is uncertain of success and may involve risks, accepting responsibility for the taking of risks affecting their own lives, and living with the consequences of their choices'. ${ }^{46}$ That said, Montgomery recognises that, in exceptional circumstances, doctors may legitimately withhold information under cover of the so-called 'therapeutic privilege'. However, the Court emphasises that this exception 'is not intended to subvert [the general principle] by enabling the doctor to prevent the patient from making an informed choice where she is liable to make a choice which the doctor considers to be contrary to her best interests'. ${ }^{47}$ In short, patients have a right to make their own judgments, prudential and moral, of what is in their best interests; ${ }^{48}$ and it is the responsibility of doctors not to override these judgments but to assist patients by ensuring that their choices are suitably informed.

While each case must be judged on its own particular facts, there is no suggestion that Montogmery is an exceptional decision with little precedent value. Nevertheless, even if

\footnotetext{
$44 \quad$ [2015] UKSC 11, para 76.

$45 \quad$ [2015] UKSC 11, para 78.

$46 \quad$ [2015] UKSC 11, para 81.

$47 \quad$ [2015] UKSC 11, para 91.

48

Nb Lady Hale in Montgomery at para 115.
} 
Montgomery is the landmark decision that it seems to be, the extent to which it supports the claimed rights is open to interpretation.

\subsection{Montgomery and the right to know}

After Montgomery, we can take it that, at all stages of a pregnancy, whether in the ante-natal screening clinic or in the delivery room, a woman has a right to be informed about the options that are available to her. It follows that, once NIPT is embedded in the screening pathway, pregnant women will have a right to know about the availability of the test, to be informed about the risks and consequences of having the test, and following the test to be informed about the results and the further options. As we have said, however, it seems unlikely that there will be any opposition to this articulation of the right to know (in relation to the primary results); and, the fact that Montgomery supports this incarnation of the right is probably not significant. The real question is whether Montgomery supports a more extended application of the right to know.

Suppose, for example, the test used by NHS screeners might also reveal a potentially lifethreatening condition that affects the mother. While Montgomery might be thought to assist the mother's claimed right to know, the decision of the High Court in $A B C v$ St George's Healthcare NHS Trust ${ }^{49}$ will give us pause. There, the claimant, who was pregnant at the relevant time, brought an action in negligence against the defendants, complaining that they had failed to inform her that her father had been diagnosed with Huntington's Disease. Had the claimant been so informed, she would have known that she was at risk of having the disease and, knowing that her children would also be at risk, she would have terminated the pregnancy. In response, the defendants advanced a catalogue of reasons why it would not be fair, just, and reasonable to impose the duty. In one way or another, these reasons all hinged 
on the fact that the defendants obtained the information about the father's health status in confidence. To tell the claimant daughter that her father had Huntington's Disease would be to break the confidence; and English law sets the bar very high before a confidence may be broken - indeed, higher than that set by bodies such as the Human Genetics Commission, the Nuffield Council on Bioethics and the GMC (where the importance of alerting family members to genetic risks is recognised).

Faced with this barrage of arguments favouring respecting the confidence, coupled with the absence of a clear precedent in support of the claimant's case, Mr Justice Nicol agreed that the claim should be struck out. In the circumstances, the judge held that it manifestly would not be fair, just, and reasonable to impose on the defendants a duty to inform the daughter. However, it is not clear whether the court (i) declined to recognise a prima facie duty to inform or (ii) recognised a (weak) prima facie duty to inform but treated it as outweighed by a (stronger) conflicting duty of confidence. While, from the claimant's perspective, it matters little whether the court reasoned in the first or the second way, in relation to our screening hypothetical (where there is no issue of confidentiality) it would matter quite a lot if the court rejected any such prima facie duty. ${ }^{50}$

Changing the hypothetical, suppose that the test used by NHS screeners reveals information about the fetus other than that relating to the trisomies. If the screeners decline to disclose such additional findings, it would be a stretch to suggest that Montgomery supports a claimed right to know. That said, the Supreme Court remarked that 'the courts have become increasingly conscious of the extent to which the common law reflects fundamental values, ${ }^{51}$; or, to put this more prescriptively, the courts have increasingly realised the importance of the

50 The ABC case is under appeal and, as I understand it, is due to be heard early in 2017.

51 [2015] UKSC 11, para 80. 
common law being in line with fundamental values. Taking such a cue, a court might in future start with the proposition that, if a woman wishes to access information about the genetic profile of her baby, she has a fundamental right to do so. This would suggest that the health service has a responsibility to return to the woman whatever test results are (i) relatively easy to interpret, (ii) clear as to their clinical significance, and (iii) material to the woman's decision — the Montgomery test of materiality being 'whether, in the circumstances of the particular case, a reasonable person in the patient's position would be likely to attach significance to the risk, or the doctor is or should reasonably be aware that the particular patient would be likely to attach significance to it'. ${ }^{52}$ Presumably, no reasonable person would want information on what I earlier termed the 'black list'; but, what would be the legal position if a particular woman (unreasonably) did want all results, on all lists, returned? If the scope of a right to be informed follows closely the contours of the Montgomery case, it might well be that it extends only to results on the 'white list' ${ }^{53}$ However, if the reference point for a right to be informed is not restricted by Montgomery, it might be that it extends to the grey list or even to the full spectrum of results including data on the black list.

Having discussed at some length the significance of Montgomery relative to the right to know in the context of screening and reproductive decisions, what application, if any, does it have to biobanking? Some will give this question short shrift: Montgomery, it will be said, has no such application; the facts of Montgomery raised a question about clinical options, and even the more general principles - the new approach — concern the relationship between doctors and patients. Questions arising in a research context are simply not on the radar.

\footnotetext{
[2015] UKSC 11, para 87. being given in a from that is understandable and with a view to aiding the patient's understanding.
} 
From a narrow legal perspective, this assessment seems correct. If Montgomery were to be cited in a claim made against a biobank or a biobank researcher, it would be easy to distinguish it; and even if the line between what is clinical and what is research is a bit hazy, it serves to confine the application of the new approach. Nevertheless, this surely plays down the significance of the Supreme Court's recognition of persons such as patients having rights; participants in research trials or studies, too, would be seen as having rights. It does not follow, of course, that they have a right to know. However, to repeat a point already made, where the information over which a participant claims to have a right to know is potentially life-saving, it seems an abdication of the researchers' responsibilities if they can decline to return findings because it might involve a minor inconvenience or a slight disruption to the research project. Indeed, if the courts are already aware of the importance of the common law aligning with fundamental values, and if one of our fundamental values is that we should assist others in need, then even before Montgomery one might think that a claim of this kind should succeed. ${ }^{54}$

\subsection{Montgomery and the right not to know}

In Montgomery, we read that '[a] person can of course decide that she does not wish to be informed of risks of injury (just as a person may choose to ignore the information leaflet enclosed with her medicine). ${ }^{55}$ This might be read as saying no more than that a person who has the right to know may elect not to inform themselves; and, given that Montgomery is concerned with providing rather than not providing information, this might be all that the Court means. Accordingly, we need to be careful not to make too much of Montgomery in relation to the claimed right not to know.

\footnotetext{
54 On the responsibility to assist, see R. Brownsword, 'The Ancillary Care Responsibilities of Researchers: Reasonable but Not Great Expectations' (2007) 35 Journal of Law, Medicine and Ethics 679. 
In the context of screening and the use of NIPT, we do not know how far Montgomery might support the right to know; however, we do know that the right to know is only likely to be a real issue where the practice is not to return findings that pregnant women wish to have. Similarly, although Montgomery is hard to interpret on the right not to know, we do know that the right not to know is only likely to become a real issue where the practice is to return findings. Provided that the options that are available are set out and a woman then rejects an option for the return of findings, the thinking in Montgomery suggests that, on the one side, health care professionals must restrain any paternalistic impulses that they might have, and, on the other, the woman must live with the consequences of her decision.

Yet, it might not be quite so easy to turn back the tide of genetic information. For example, the costs and inconvenience of administering a right not to know might not be trivial; professionals might find it difficult to accept that they should act as though patients know best when in their expert judgment they manifestly do not; and, for all we know, the culture of reproduction in future communities might be so risk-averse that the general view is that parents should not be permitted to shirk their responsibilities by claiming a right not to know. $^{56}$

Much the same applies to the right not to know in the context of biobanking, where the application of Montgomery is even less clear. Here, again, a participant's (or a prospective participant's) claimed right not to know is only likely to present a real issue when the practice at biobanks shifts from no feedback to feedback, or where the volume and nature of findings that are returned changes. For example, while UK Biobank is now undertaking a major

56 Compare H.T. Greely, The End of Sex and the Future of Human Reproduction (Cambridge, Mass.: Harvard University Press, 2016). See, too, Heywood (n 41) who says at 465:

Depending upon how the decision in Montgomery is explained to health-care providers, and how it subsequently comes to be understood, it is not beyond the realms of possibility to envisage a scenario in which health-care professionals are prone to disclose what might best be described as excessive information, which some patients may not necessarily need or, worse still, want. 
imaging sub-study that retains the general rule of 'no feedback' in relation to research findings, there is a procedure for returning potentially significant clinical findings arising (incidentally) from the taking of the scans and images. ${ }^{57}$ The participant information outlines this procedure in the following terms:

The technicians conducting the scans will be looking at the images to ensure their quality. It is important to understand that they will not be looking at them to identify particular health problems. However, if a technician does notice something unusual that they think might be serious they will refer that scan to a specialist doctor for review. Something would be considered potentially serious if it indicated the possibility of a condition which, if confirmed, would carry a real prospect of seriously threatening life span, or of having a substantial impact on major body functions or quality of life. If the specialist doctor agrees that the abnormality may be serious (regardless of whether or not it can be treated), then we will write to you and your GP (usually within two weeks of your visit). ${ }^{58}$

Crucially, those who agree to participate in the imaging study are not given the option of opting out. Accordingly, the information sheet emphasises that a prospective participant should only agree to participate 'if you feel able to consent to both you and your GP being informed if a potentially serious abnormality is noticed on one of your scans. ${ }^{59}$ For those who are concerned about the prospect of being presented with unwelcome information, possibly raising anxiety unnecessarily, and possibly of uncertain significance, the advice is to think very hard before agreeing to participate. ${ }^{60}$ Unless we think that we should have (i) a

\footnotetext{
57 See http://imaging.ukbiobank.ac.uk/ (last accessed September 25, 2016).

58 Information leaflet at p. 12: accessed via http://imaging.ukbiobank.ac.uk/.

59 Information leaflet, at p. 13: accessed via http://imaging.ukbiobank.ac.uk/. Ibid.
} 
right to participate in biobank projects, coupled with (ii) a right to opt-out from the return of findings, declining to participate is an effective and an acceptable way of protecting oneself against the genetic tides. However, this is far from ideal and, if this happens on a large scale, biobanks might follow the Estonian model and grant a right to opt out from the return of findings. In any event, Montgomery probably offers little assistance to those who wish to assist researchers but without having to cope with genetic information that they prefer not to have. Accordingly, if the question is whether we should recognise a right to participate together with a right to opt out from the return of findings, then Montgomery is probably not where we will find the answer.

\section{Concluding Remarks}

As genetic tests become even cheaper and as the interpretation of results becomes more reliable and actionable, it seems likely that some humans will want to know the results of such tests and others will not. Whether or not humans will be entitled to insist on knowing or not knowing, remains to be seen; much will turn on whether a right to know and a right not to know is recognised. We can be confident, I suggest, that we have not heard the last of these rights. Accordingly, let me conclude with three short general remarks.

First, the claimed right to know seems particularly compelling where it relates to information that is personal (being 'about me') rather than being about others or other things. Arguably, however, there is also an important distinction between claiming the rights in order to define or maintain one's personality (or sense of identity) and claiming the rights in relation to personal information for other purposes. It is in the former that we find a common basis for (but not necessarily symmetrical articulation of) these rights. That said, these short thoughts raise questions about both the basis of the claimed rights and their relationship with one another that invite further analysis. 
Secondly, as genetic information becomes more widely distributed, accessible and interpretable, the default in health care will be for each person to be aware of their genetic profile such that those who need to assert a right to know will be pushing at an open door; but, at the same time, for those who prefer to lead their lives without having to assess and micro-manage their particular genetic risks, the right not to know will be their protective shield. In the longer run, therefore, it is the basis, strength and scope of the right not to know that needs to be most clearly articulated. ${ }^{61}$

Thirdly, while the decision in Montgomery is open to interpretation ${ }^{62}$, perhaps its enduring significance is not so much that there is a right to be informed about one's treatment options but simply that patients have rights. ${ }^{63}$ With this support from Montgomery it becomes clear that the regulatory environment for healthcare, including screening and biobanking, has to protect, preserve and promote the rights of patients and participants. To what extent that environment should respect the claimed right to know and not to know is a matter for continuing debate; but this is now a debate for a community that is committed to rights, not for a community that is inclined to default to physician paternalism, professional duties, risk/benefit calculations, or the general utility. ${ }^{64}$

61 Compare R. C. Green et al, 'ACMG Recommendations for Reporting of Incidental Findings in Clinical Exome and Genome Sequencing’ available at http://www.acmg.net/docs/ACMG_Releases_HighlyAnticipated_Recommendations_on_Incidental_Findings_in_Clinical_Exome_and_Genome_Sequencin g.pdf (last accessed July 24, 2013), where, at 11, it is recognised that the Recommendations 'may be seen to violate existing ethical norms regarding the patient's autonomy and "right not to know" genetic risk information'.

For an important review of the facts, see J. Montgomery and E. Montgomery, 'Montgomery on informed consent: an inexpert decision?' (2016) $42 \mathrm{~J}$ Med Ethics 89.

See Heywood (n 41) at 462-464.

For helpful reflections on the values that shape EU governance of public health, see Mark Flear, Governing Public Health (Oxford: Hart, 2015). 